\title{
Antifungal Prophylaxis with Posaconazole versus Fluconazole in Children with Neutropenia Following Allogeneic Hematopoietic Stem Cell Transplantation: Single Center Experience
}

\author{
Chayamon Takpradit (1D' \\ Chonthida Wangkittikal ${ }^{2}$ \\ Supattra Rungmaitree ${ }^{3}$ \\ Jassada Buaboonnam ' \\ Nattee Narkbunnam' \\ Kamon Phuakpet' \\ Nassawee Vathana' \\ Kleebsabai Sanpakit (DD' \\ Bunchoo Pongtanakul (D)' \\ 'Division of Hematology and Oncology, \\ Department of Pediatrics, Faculty of \\ Medicine Siriraj Hospital, Mahidol \\ University, Bangkok, Thailand; ${ }^{2}$ Division \\ of Hematology and Oncology, \\ Department of Pediatrics, Chonburi \\ Hospital, Chonburi, Thailand; ${ }^{3}$ Division of \\ Pediatric Infectious Diseases, \\ Department of Pediatrics, Faculty of \\ Medicine Siriraj Hospital, Mahidol \\ University, Bangkok, Thailand
}

\begin{abstract}
Background: Invasive fungal diseases (IFDs) are common and contribute to mortality in patients undergoing hematopoietic stem cell transplantation (HSCT). The relative efficacies of posaconazole (POS) and fluconazole (FLU) as primary antifungal prophylaxes are uncertain.
\end{abstract}

Methods: A retrospective study was performed on children treated with allogeneic HSCT who received POS or FLU during the early neutropenic period. The efficacies, safety, and tolerabilities of the prophylaxes were compared.

Results: Data on 78 HSCT recipients were analyzed. Most had thalassemia (58\%). Preengraftment, POS and FLU were administered to 41 and 37 cases, respectively. There were no proven cases of IFD. However, 2 POS cases and 1 FLU case had probable IFDs. The IFD incidences of the POS (5\%) and FLU (3\%) groups demonstrated no statistical difference ( $p=$ 0.620). Of the 75 surviving cases receiving FLU post-engraftment (including 39 cases previously given POS), 3 had proven IFDs whereas 3 had probable IFDs (total, 6 [8\%]) within 1 year post-HSCT. No cases discontinued the prophylaxes due to drug intolerance. The common adverse events with POS and FLU were not significantly different. Only 19\% of the patients achieved the therapeutic POS level, with a starting dose of $4 \mathrm{mg} / \mathrm{kg}$ thrice daily.

Conclusion: POS and FLU demonstrate comparable levels of effectiveness, safety, and tolerability as IFD prophylaxes for neutropenic children treated with allogeneic HSCT. Determination of the optimum POS dose and duration requires larger studies.

Keywords: antifungal prophylaxis, children, fluconazole, hematopoietic stem cell transplantation, posaconazole

\section{Introduction}

Invasive fungal diseases (IFDs) are leading causes of mortality in patients receiving hematopoietic stem cell transplantations (HSCTs). Several studies reported that the IFD incidence in HSCT recipients ranged from $6 \%$ to $33 \%$ and was associated with grave prognoses. ${ }^{1-4}$ Candida and Aspergillus species, the 2 most commonly encountered fungal pathogens, ${ }^{1,2}$ have high mortality rates $(49 \%$ and $67 \%$, respectively). ${ }^{5}$ Our hospital has also reported the incidence of IFD among adult patients with hematological malignancies. Candidiasis was the most common pathogen $(63 \%)$, followed by aspergillosis $(26 \%){ }^{6}$
Correspondence: Bunchoo Pongtanakul Division of Hematology and Oncology, Department of Pediatrics, Faculty of Medicine Siriraj Hospital, Mahidol University, 2 Wanglang Road, Bangkok Noi, Bangkok, 10700, Thailand

Tel +66 2-4l9-597|

Fax +66 2-866-302I

Email pongtanakul@yahoo.com 
Since the 1990s, fluconazole (FLU) has been the drug of choice as the primary prophylaxis against invasive candidiasis for allogeneic HSCT recipients. ${ }^{7}$ However, the major drawback of FLU is that it demonstrates no antimicrobial activity against molds. To overcome this problem, posaconazole (POS), an oral suspension of an azole mold-active prophylaxis agent, has been utilized. Several studies (mostly in adult HSCT recipients) reported that POS produced superior outcomes to FLU-including a lower mortality rate- for the prevention of IFDs. ${ }^{8,9}$

On the other hand, POS may exhibit erratic absorption, and it requires therapeutic drug monitoring. The pharmacokinetics of POS in the pediatric population remains limited. ${ }^{10,11}$ Promising results were shown for immunocompromised pediatric patients, with no serious adverse events related to POS being observed. ${ }^{12-14}$ There is a recommendation to administer a mold-active agent with an echinocandin or a mold-active azole when systemic antifungal prophylaxis is warranted. For children younger than 13 years of age, echinocandin, voriconazole, or itraconazole is suggested. POS may also be used in those aged 13 years or older. ${ }^{15}$ The oral suspension of POS has been available at our institute since 2012. We report the incidence and outcomes of IFDs, and the safety and tolerability of using either POS or FLU, for pediatric patients (aged 0-18 years) who underwent allogeneic HSCTs at our center.

\section{Patients and Methods}

We retrospectively analyzed the medical records of 78 Siriraj Hospital patients aged $0-18$ years who underwent allogeneic HSCTs, with either FLU or POS as their primary IFD prophylaxis, between 2000 and 2019. A combination of calcineurin inhibitors and short-course methotrexate was administered to the patients as a graft-versus-host disease (GvHD) prophylaxis. Active surveillance to identify the adverse events during the HSCTs was undertaken. The trough level of cyclosporine (CsA), between 200 and 400 $\mathrm{ng} / \mathrm{mL}$, was monitored after 2004, and cytomegalovirus viral-load testing was available from 2006. Filgrastim was given once daily at $10 \mathrm{mcg} / \mathrm{kg}$ IV from Day +1 until the absolute neutrophil count reached $\geq 1 \times 10^{3} / \mathrm{uL}$ for at least 2 consecutive days. Broad-spectrum antibiotics were administered for the treatment of febrile neutropenia. An antifungal prophylaxis - either POS or FLU — was commenced on Day +1 after the stem cell infusion and continued until engraftment. Between 2000 and 2011, FLU $(10 \mathrm{mg} / \mathrm{kg})$ was administered orally or intravenously (depending on a patient's status) once daily for all patients receiving HSCTs. After
2012, however, all HSCT patients were given POS as an oral suspension at the dose of $4 \mathrm{mg} / \mathrm{kg}$, thrice daily with meals. The POS level was determined on Day +5 post-HSCT and adjusted dose to the target trough levels of $\geq 0.7 \mathrm{mg} / \mathrm{L}$. Postengraftment, all patients in the POS group were changed to FLU until cessation of immunosuppression due to financial constraints. The post-engraftment period for patients with FLU started one day after evidence of neutrophil engraftment.

The primary analysis compared the incidences of proven and probable IFDs during the pre-engraftment phase. The diagnosis of IFDs was made by a pediatric infectious-disease specialist team. The secondary analysis focused on 2 aspects. The first was identification of adverse events that were possibly related to the antifungal agents, such as nausea, diarrhea, exanthema, elevated transaminase levels, and renal insufficiency. We categorized the subgroup analysis to identify liver toxicity and CsA level, based on antifungal exposure and POS levels: (1) POS $\geq 0.7 \mathrm{ng} / \mathrm{mL}$ group; (2) POS $<0.7 \mathrm{ng} / \mathrm{mL}$ group; and (3) FLU group. The second aspect was the incidence of IFDs during the post-engraftment period among 2 sets of patients: those administered POS pre-engraftment and FLU post-engraftment, and those receiving FLU from the outset. Approval for the study was obtained from Siriraj Institutional Review Board/Privacy Board (716/ 2560 [EC2]). The need for consent forms was waived, given that the study was conducted retrospectively. We declared that the patient data confidentiality complied with the Declaration of Helsinki.

\section{Definitions}

Adverse events were graded according to the Common Terminology Criteria for Adverse Events (version 5.0). ${ }^{16}$ IFDs were categorized as proven and probable, as per the European Organization for Research and Treatment of Cancer and the Mycoses Study Group Education and Research Consortium (EORTC/MSGERC) 2019 definitions. ${ }^{17}$ The IFD outcomes followed the criteria specified in the EORTC/MSGERC criteria. ${ }^{18}$

\section{Statistical Analysis}

The statistical analyses were performed using IBM SPSS Statistics for Windows (version 26.0; IBM Corp., Armonk, NY, USA). In comparisons of the 2 treatments, a chisquared test or Fisher's exact test was used for qualitative variables, whereas a two-sample $t$-test and the MannWhitney $U$-test were used for quantitative variables with 
and without normal distribution, respectively. KaplanMeier curves were used to present the cumulative incidence of time-to-event data from the dates of the HSCTs, and the curves were compared using the Log rank test. All $p$ values were 2-tailed, and $p<0.05$ was considered statistically significant. The Kruskal-Wallis test was used to compare the baseline and maximum levels of total bilirubin, direct bilirubin, alanine transaminase, and aspartate transaminase. The CsA levels during the antifungal prophylaxis were analyzed using one-way ANOVA. Graphs were created with GraphPad Prism for Mac (version 8.4; GraphPad Software, San Diego, CA, USA).

\section{Results}

\section{Patient Characteristics}

The analysis used data from 78 patients (49 males and 29 females), with a median age at HSCT of 7.5 years (range, 1.4 to 17.7). During the pre-engraftment period, 41 patients (53\%) received POS (the POS group), while 37 (47\%) received FLU (the FLU group). The patient characteristics are listed in Table 1. Hematological malignancy was significantly higher for the POS group ( $p=0.043)$, while non-hematological malignancy was higher for the FLU group ( $p=0.043)$. The stem cell source differed between the 2 groups $(p=0.002)$, as did the median

Table I Patient and Transplant Characteristics

\begin{tabular}{|c|c|c|c|c|}
\hline Variable & POS & FLU & Total & $P$ value \\
\hline Number of patients; no. (\%) & $41(53)$ & $37(47)$ & 78 & \\
\hline Male sex; no. (\%) & $26(63)$ & $23(62)$ & $49(63)$ & 0.909 \\
\hline Age; median (range) in year & $7.7(\mid .4-17.7)$ & $7.0(1.4-14.7)$ & $7.5(1.4-17.7)$ & 0.337 \\
\hline \multicolumn{5}{|l|}{ Primary disease; no. (\%) } \\
\hline $\begin{array}{l}\text { Hematological malignancy } \\
\text { Relapsed/refractory ALL } \\
\text { AML } \\
\text { Relapsed/refractory AML } \\
\text { Biphenotypic leukemia } \\
\text { Histiocytic sarcoma } \\
\text { CML } \\
\text { JMML } \\
\text { Lymphoma }\end{array}$ & $\begin{array}{l}15(37) \\
5(12) \\
4(10) \\
2(5) \\
1(2) \\
1(2) \\
0 \\
I(2) \\
\text { I (2) }\end{array}$ & $\begin{array}{l}6(16) \\
3(8) \\
0 \\
1(3) \\
0 \\
0 \\
1(3) \\
1(3) \\
0\end{array}$ & $\begin{array}{l}21(27) \\
8(10) \\
4(5) \\
3(4) \\
1(1) \\
1(1) \\
1(1) \\
2(3) \\
1(1)\end{array}$ & $\begin{array}{c}0.043^{\mathrm{a}} \\
0.631 \\
0.280 \\
0.843 \\
0.517 \\
0.517 \\
0.286 \\
0.5 \\
0.517\end{array}$ \\
\hline $\begin{array}{l}\text { Non-hematological malignancy } \\
\text { Thalassemia } \\
\text { Aplastic anemia } \\
\text { Immunodeficiency diseases } \\
\text { IBMFS }\end{array}$ & $\begin{array}{c}25(6 \mathrm{I}) \\
20(49) \\
3(7) \\
I(2) \\
I(2)\end{array}$ & $\begin{array}{l}31(84) \\
25(68) \\
4(1 \mathrm{I}) \\
I(3) \\
I(3)\end{array}$ & $\begin{array}{l}56(72) \\
45(58) \\
7(9) \\
2(3) \\
2(3)\end{array}$ & $\begin{array}{l}0.043 \\
0.952 \\
0.919 \\
0.877 \\
0.877\end{array}$ \\
\hline Solid tumors & I (2) & 0 & $I(I)$ & 0.345 \\
\hline $\begin{array}{l}\text { Donor; no. (\%) } \\
\text { MRD } \\
\text { MMRD } \\
\text { MUD } \\
\text { MMUD }\end{array}$ & $\begin{array}{c}23(56) \\
2(5) \\
12(29) \\
4(10)\end{array}$ & $\begin{array}{c}28(75) \\
0 \\
8(22) \\
1(3)\end{array}$ & $\begin{aligned} 51 & (65) \\
2 & (3) \\
20 & (26) \\
5 & (6)\end{aligned}$ & 0.179 \\
\hline $\begin{array}{l}\text { CMV serostatus; no. (\%) } \\
\text { D+ R- } \\
\text { D+ R+ } \\
\text { D- R+ } \\
\text { D- R- }\end{array}$ & $\begin{array}{c}4 \mathrm{I} \\
4(10) \\
25(6 \mathrm{I}) \\
9(22) \\
3(7)\end{array}$ & $\begin{array}{l}29^{\mathrm{b}} \\
2(7) \\
13(45) \\
11(38) \\
3(10)\end{array}$ & $\begin{array}{c}70 \\
6(9) \\
38(54) \\
20(28) \\
6(9)\end{array}$ & 0.444 \\
\hline
\end{tabular}

(Continued) 
Table I (Continued).

\begin{tabular}{|c|c|c|c|c|}
\hline Variable & POS & FLU & Total & $P$ value \\
\hline \multicolumn{5}{|l|}{ Stem cell source; no. (\%) } \\
\hline Bone marrow & $19(46)$ & $30(8 I)$ & $49(63)$ & 0.002 \\
\hline Peripheral blood & $22(54)$ & $7(19)$ & $29(37)$ & \\
\hline \multicolumn{5}{|l|}{ Conditioning regimen; no. (\%) } \\
\hline MAC & $36(88)$ & $34(92)$ & $70(90)$ & 0.714 \\
\hline RIC & $5(12)$ & $3(8)$ & $8(10)$ & \\
\hline \multicolumn{5}{|l|}{ GvHD prophylaxis; no. (\%) } \\
\hline$M T X+C s A$ & $37(90)$ & $35(95)$ & $72(92)$ & 0.677 \\
\hline MTX+MMF+Tacro & $4(10)$ & $2(5)$ & $6(8)$ & \\
\hline Duration of neutropenia ANC $<500 /$ cumm; median (range) in days & $16(6-35)$ & $14(3-33)$ & $16(3-35)$ & 0.323 \\
\hline Day of engraftment; median (range) & Day +19 (II-44) & Day $+24(14-35)$ & Day +2I (II-44) & 0.002 \\
\hline Hospitalization; median number of days (range) & $79(33-232)$ & $88(45-258)$ & $80(33-258)$ & 0.126 \\
\hline Acute GvHD; no. (\%) & II (27) & $10(27)$ & $21(27)$ & 0.984 \\
\hline Grades I-II & $7(64)$ & $9(90)$ & $16(76)$ & 0.311 \\
\hline Grades III-IV & $4(36)$ & $\mathrm{I}(\mathrm{I0})$ & $5(24)$ & \\
\hline Chronic GvHD; no. (\%) ${ }^{c}$ & $10(26)$ & $4(11)$ & $14(19)$ & 0.142 \\
\hline Limited & $I(10)$ & $2(50)$ & $3(21)$ & 0.176 \\
\hline Extensive & $9(90)$ & $2(50)$ & II (79) & \\
\hline \multicolumn{5}{|l|}{ Outcome; no. (\%) } \\
\hline Alive & $31(76)$ & $30(8 I)$ & $61(78)$ & 0.594 \\
\hline Death & $10(24)$ & $7(19)$ & $17(22)$ & \\
\hline Follow-up time; median (range) in years & $1.9(0.6-7.7)$ & $9.9(1-20)$ & $3.3(0.6-20)$ & $<0.001$ \\
\hline
\end{tabular}

Notes: ${ }^{\mathrm{a}}$ Two-tailed $p$ value compared no. with hematological malignancy vs non-hematological malignancy, ${ }^{\mathrm{b}} \mathrm{CMV}$ status in FLU group available for 29 of 37 patients, 'Posaconazole $\mathrm{n}=39$; fluconazole $=36$; total $=75$.

number of days to engraftment $(p=0.002)$. The durations of neutropenia in the 2 groups were comparable, with 16 days (range, 6 to 35) for the POS group and 14 days (range, 3 to 33 ) for the FLU group $(p=0.323)$. Graft failure was evident for 2 severe aplastic anemia patients (one from each group).

\section{Toxicity, Complications, and Outcomes}

There were no significant differences in the acute toxicity of the POS and FLU groups except for cytomegalovirusinfection reactivation ( $p=0.038$; Table 2$)$. The most common complications were febrile neutropenia, mucositis, and elevated liver enzymes.

The CsA trough level was available for 58 of the total of 72 patients $(81 \%)$ who received methotrexate plus CsA as a GvHD prophylaxis. The median CsA level was 125.5 $\mathrm{ug} / \mathrm{L}$ (range, 31 to 533) for the POS group, and $119 \mathrm{ug} / \mathrm{L}$ (range, 37 to 333) for the FLU group. Nine of the 33 POS patients $(27 \%)$ and 3 of the 25 FLU patients (12\%) achieved the therapeutic CsA level; however, most patients in both groups had a CsA level of $<200 \mathrm{ug} / \mathrm{L}$. Three patients (9\%) in the POS group had a maximum CsA level exceeding $400 \mathrm{ug} / \mathrm{L}$, but without evidence of hypertension or renal insufficiency; all 3 reached the therapeutic range after a dose reduction.

The POS trough level was checked in 37 of 41 patients $(90 \%)$ in the POS group. Their median POS level was 0.5 $\mu \mathrm{g} / \mathrm{mL}$ (range, 0.1 to 1.02 ). Seven of the patients $(19 \%$ ) reached the therapeutic level from the starting dose. After a dose adjustment, a further 7 patients (23\%) reached the target level.

The 2-year IFD-free overall survival rates of the POS and FLU groups were comparable at $87.8 \%$ and $88 \%$, respectively ( $p=0.507$; Figure $1 \mathrm{~A}$ ). However, subgroup analyses showed significant differences in the overall survival rates of 4 groups of patients: (1) POS with a hematological malignancy, $73.9 \%$; (2) POS with a nonhematological malignancy (NHMD), 78.6\%; (3) FLU with 
Table 2 Patient-Reported, and Treatment-Emergent, Complications During the Pre-Engraftment Phase

\begin{tabular}{|c|c|c|c|c|}
\hline Variable - no. (\%) & POS $(N=4 I)$ & FLU $(\mathbf{N}=37)$ & Total $(\mathbf{N}=\mathbf{7 8})$ & $P$ value \\
\hline Oral mucositis & $29(7 \mathrm{I})$ & $24(65)$ & $53(68)$ & 0.632 \\
\hline Nausea/vomiting & $3(7)$ & $2(5)$ & $5(6)$ & 0.731 \\
\hline Non-infectious diarrhea & $12(29)$ & $8(22)$ & $20(26)$ & 0.604 \\
\hline Exanthema & $5(12)$ & $3(8)$ & $8(10)$ & 0.715 \\
\hline Hypertension & $16(39)$ & $9(24)$ & $25(32)$ & 0.225 \\
\hline Engraftment syndrome & $5(12)$ & $2(5)$ & $7(9)$ & 0.436 \\
\hline Sinusoidal obstruction syndrome & $7(17)$ & $7(19)$ & $14(18)$ & 0.832 \\
\hline Gl bleeding & $3(7)$ & $2(5)$ & $5(6)$ & 0.731 \\
\hline AST/ALT increased & $2 I(5 I)$ & $20(54)$ & $41(53)$ & 0.824 \\
\hline Hypokalemia & $3(7)$ & $3(8)$ & $6(8)$ & 0.896 \\
\hline Acute kidney injury & $13(32)$ & $8(22)$ & $21(27)$ & 0.444 \\
\hline Febrile neutropenia & $30(73)$ & $22(59)$ & $52(67)$ & 0.235 \\
\hline Septicemia & $16(39)$ & $13(35)$ & $29(37)$ & 0.816 \\
\hline Gram-negative septicemia & $14(34)$ & $9(24)$ & $23(29)$ & 0.457 \\
\hline Escherichia coli & $5(36)$ & $2(22)$ & $7(31)$ & 0.657 \\
\hline Escherichia coli ESBL & $4(29)$ & $5(56)$ & $9(39)$ & 0.383 \\
\hline Klebsiella pneumoniae & I (7) & $\mathrm{I}(\mathrm{II})$ & $2(9)$ & 0.742 \\
\hline Pseudomonas aeruginosa & I (7) & 0 & I (4) & 0.412 \\
\hline Stenotrophomonas maltophilia & 0 & $\mathrm{I}(\mathrm{II})$ & I (4) & 0.391 \\
\hline Acinetobacter baumannii & $3(2 I)$ & 0 & $3(13)$ & 0.253 \\
\hline Gram-positive septicemia & $6(15)$ & $7(19)$ & $13(17)$ & 0.763 \\
\hline MRCNS & $I(I 7)$ & $2(29)$ & $3(23)$ & 0.611 \\
\hline MRSA & 0 & I (14) & I (8) & 0.335 \\
\hline MSSA & $\mathrm{I}(17)$ & 0 & I (8) & 0.462 \\
\hline Corynebacterium & $2(32)$ & 0 & $2(15)$ & 0.192 \\
\hline Streptococcus pneumoniae & $\mathrm{I}(\mathrm{I7})$ & $2(29)$ & $3(23)$ & 0.611 \\
\hline Streptococcus viridans & 0 & I (14) & I (8) & 0.335 \\
\hline Bacillus cereus & $\mathrm{I}(\mathrm{I7})$ & I (14) & $2(15)$ & 0.906 \\
\hline Mucocutaneous candidiasis & $5(12)$ & 7 (19) & $12(15)$ & 0.534 \\
\hline CMV infection reactivation & $2 I(5 I)$ & $10(27)$ & $31(39)$ & 0.038 \\
\hline Herpes simplex reactivation & $4(10)$ & $4(\mathrm{II})$ & $8(10)$ & 0.878 \\
\hline Shingles & $3(7)$ & $3(8)$ & $6(8)$ & 0.896 \\
\hline Pneumonia & II (27) & $10(27)$ & $21(27)$ & 0.984 \\
\hline Urinary tract infection & $7(17)$ & $6(16)$ & $13(17)$ & 0.919 \\
\hline Infectious diarrhea & $7(17)$ & $3(8)$ & $10(13)$ & 0.317 \\
\hline Clostridium difficile & I (14) & I (33) & $2(20)$ & 0.490 \\
\hline Rotavirus & $3(43)$ & NA & $3(30)$ & NA \\
\hline Salmonella & $2(29)$ & $2(67)$ & $4(40)$ & 0.500 \\
\hline Aeromonas hydrophila & I (14) & 0 & $I(10)$ & 0.490 \\
\hline
\end{tabular}

Abbreviation: NA, not available.

a hematological malignancy, 33.3\%; and (4) FLU with NHMD, 96.8\% $(p=0.021$; Figure 1B).

Overall, 17 of the 78 patients $(21.8 \%)$ died after their HSCTs. Relapse was the leading cause of death in patients with a malignant disease, while bacterial septicemia was the major cause of death in patients with NHMD.

\section{IFDs in Pre-Engraftment Period}

The incidences and characteristics of breakthrough IFDs during the pre-engraftment period are detailed in Tables 3 and 4 (overall incidence: $4 \% ; 5 \%$ with POS vs $3 \%$ with FLU; $p=0.620)$. No proven IFD was detected in any patient. Two POS patients $(5 \%)$ and 1 FLU patient $(3 \%)$ had probable IFDs $(p=0.620)$. All 3 patients with IFDs had prolonged 

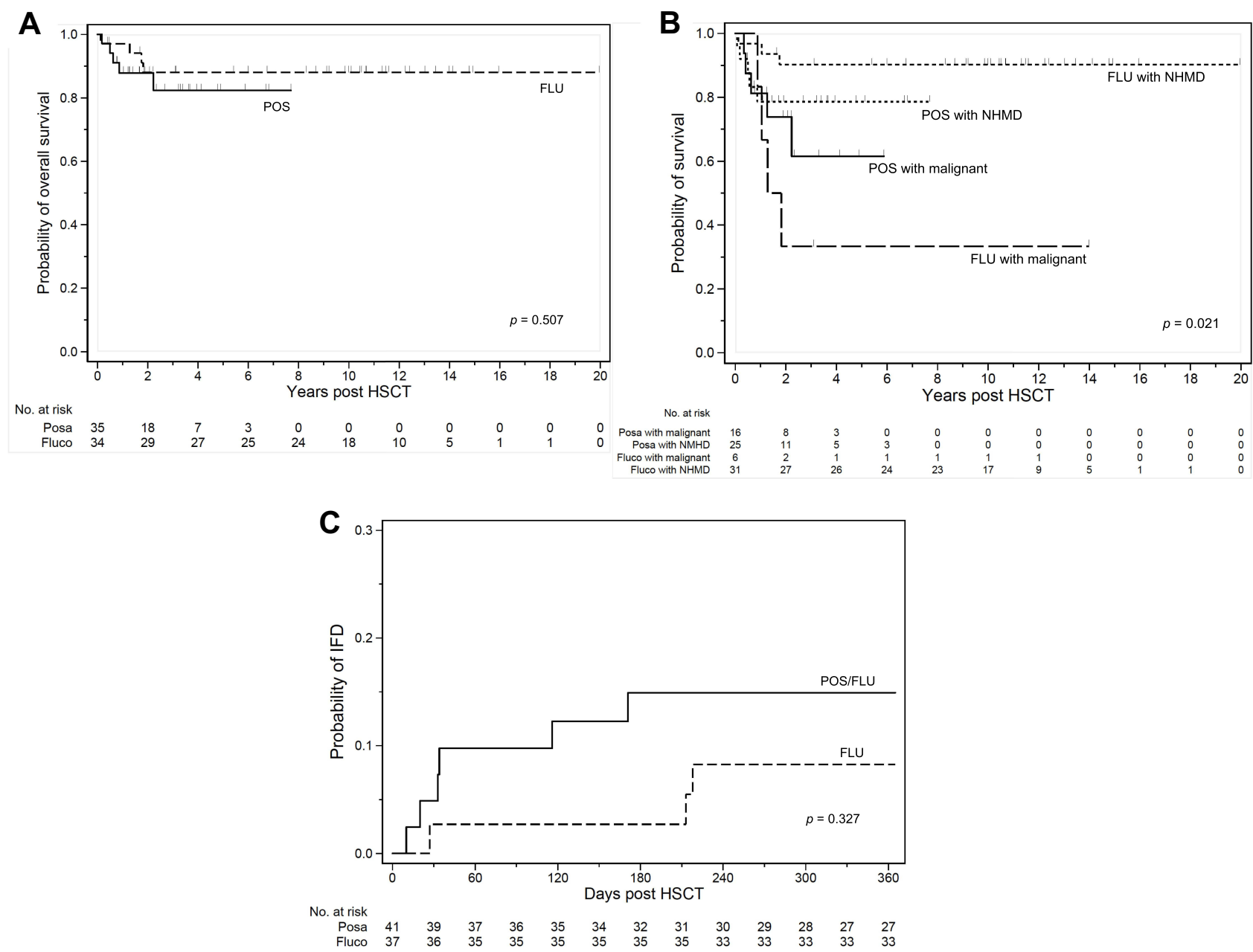

Figure I Outcomes of patients receiving allogeneic HSCT. (A) IFD-free overall survival. (B) Overall survival for patients with hematological malignancy versus nonhematological malignancy (NHMD). (C) Incidence of IFDs during the first year post-HSCT.

neutropenia. One patient from each group experienced primary graft failure, while 1 patient with POS had neutrophil engraftment on Day +14 . The IFD was diagnosed on Day +10 and Day +20 for the 2 patients with POS, and on Day +27 for the 1 patient with FLU. The 2 POS patients with IFDs had POS levels of 0.6 and $0.5 \mu \mathrm{g} / \mathrm{mL}$.

All 3 probable-IFD patients had pulmonary symptoms, with evidence of consolidation by CT scan plus a positive serum galactomannan assay. Patient 1 with POS had a partial response after 4 weeks of broad-spectrum antifungal therapy. However, he suffered a primary graft failure and died 2 months post-HSCT because of Acinetobacter baumannii septicemia. Patient 2 with POS developed grade 4 aGvHD on Day +32 post-HSCT. She required a combination of corticosteroid plus CsA to treat the aGvHD. A CT scan revealed the disappearance of lung infiltrates after 6 weeks of voriconazole administration. Unfortunately, 4 months post-HSCT, she developed extensive cGvHD (skin, liver, eyes, and gastrointestinal tract). These symptoms were refractory to extracorporeal photopheresis, and she died 15 months post-HSCT. Patient 3 with FLU experienced a primary graft failure and had a poor response to amphotericin $\mathrm{B}$, with progressive infiltration on both lungs evident in a follow-up CT scan. He died from massive hemoptysis 5 months post-HSCT. The mortality rates related to IFDs of the POS group, the FLU group, and the total were $0 \%, 100 \%$, and $33 \%$, respectively $(p=0.333)$.

\section{Adverse Events Related to the Primary Antifungal Therapies}

No patient had to discontinued POS or FLU due to drug intolerance. There were also no significant differences in the common adverse events that were related to POS and FLU-namely, nausea ( $7 \%$ vs $5 \%)$, diarrhea (29\% vs 
Table 3 Comparison of Efficacies of Posaconazole and Fluconazole as Primary Antifungal Prophylaxes During PreEngraftment Period

\begin{tabular}{|c|c|c|c|c|}
\hline & $\begin{array}{l}\text { POS } \\
(N=4 I)\end{array}$ & $\begin{array}{l}\text { FLU } \\
(N=37)\end{array}$ & $\begin{array}{l}\text { Total } \\
(\mathbf{N}=\mathbf{7 8})\end{array}$ & $P$ value \\
\hline \multicolumn{5}{|l|}{ Invasive fungal infection } \\
\hline Total — no. (\%) & $2(5)$ & I (3) & $3(4)$ & 0.620 \\
\hline Proven & 0 & 0 & 0 & \\
\hline Probable & 2 & I & 3 & 0.620 \\
\hline \multicolumn{5}{|l|}{ Evidence of fungus } \\
\hline Culture for fungus & 0 & 0 & 0 & 0.359 \\
\hline $\mathrm{CT} / \mathrm{MRI}$ & 2 & 1 & 3 & \\
\hline Serum galactomannan & 2 & 1 & 3 & \\
\hline \multicolumn{5}{|l|}{$\begin{array}{l}\text { Broad spectrum } \\
\text { antifungal agent }\end{array}$} \\
\hline Amphotericin B & 0 & 1 & I & 0.613 \\
\hline Voriconazole & 1 & 0 & 1 & \\
\hline Micafungin & 1 & 0 & 1 & \\
\hline \multicolumn{5}{|l|}{ Outcome } \\
\hline Alive & 2 & 0 & $2(3)$ & 0.494 \\
\hline Deceased & 0 & 1 & $\mathrm{I}(\mathrm{I})$ & 0.474 \\
\hline
\end{tabular}

$22 \%$ ), exanthema ( $12 \%$ vs $8 \%$ ), and elevated transaminase levels ( $51 \%$ vs $54 \%$ ), respectively (Table 2$)$.

We categorized these 74 cases into 3 subgroups: (1) a POS $\geq 0.7 \mathrm{ng} / \mathrm{mL}$ group $(\mathrm{n}=14)$; (2) a POS $<0.7 \mathrm{ng} / \mathrm{mL}$ group $(\mathrm{n}=23)$; and (3) an FLU group $(\mathrm{n}=37)$. All patients had significantly elevated total bilirubin, direct bilirubin, and liver enzyme levels during the 30 days post-HSCT ( $p<0.05$ Supplementary Figure 1-1A, 1B, 1C and 1D). However, there were no statistical differences in the rates of rise in the liver profiles of the FLU and the 2 POS groups.

Regarding the available CsA levels, the 58 patients were classified into 3 subgroups: (1) a POS $\geq 0.7 \mathrm{ng} / \mathrm{mL}$ group ( $\mathrm{n}=14)$; (2) a POS $<0.7 \mathrm{ng} / \mathrm{mL}$ group $(\mathrm{n}=19)$; and (3) an FLU group $(\mathrm{n}=25)$. The median CsA levels of the 3 groups were comparable (Figure $2 ; p=0.270$ ). No patients in the POS $\geq 0.7$ group or the FLU group experienced a CsA overdose. On the other hand, 3 patients $(16 \%)$ in the POSA $<0.7$ group had CsA levels $>400$ ug/L; following a $25 \%$ dose reduction, their levels fell to the therapeutic range. Renal insufficiency occurred in 4 patients (29\%) from the POS $\geq 0.7$ group and 2 patients (8\%) from the FLU group; all 6 patients had CsA levels within the therapeutic range. They responded when the CsA was discontinued and replaced with MMF.

\section{Post-Engraftment Period}

IFDs occurred in 4 of the 39 patients who were given POS at the beginning of their HSCTs, and in 2 of the 36 patients who were administered FLU at the time of their HSCTs (overall incidence rate, 8\%; Figure 1C). Three patients had proven IFDs, whereas the other 3 had probable IFDs (Table 4). Two patients developed IFDs during the early post-engraftment period, while the other 4 cases were

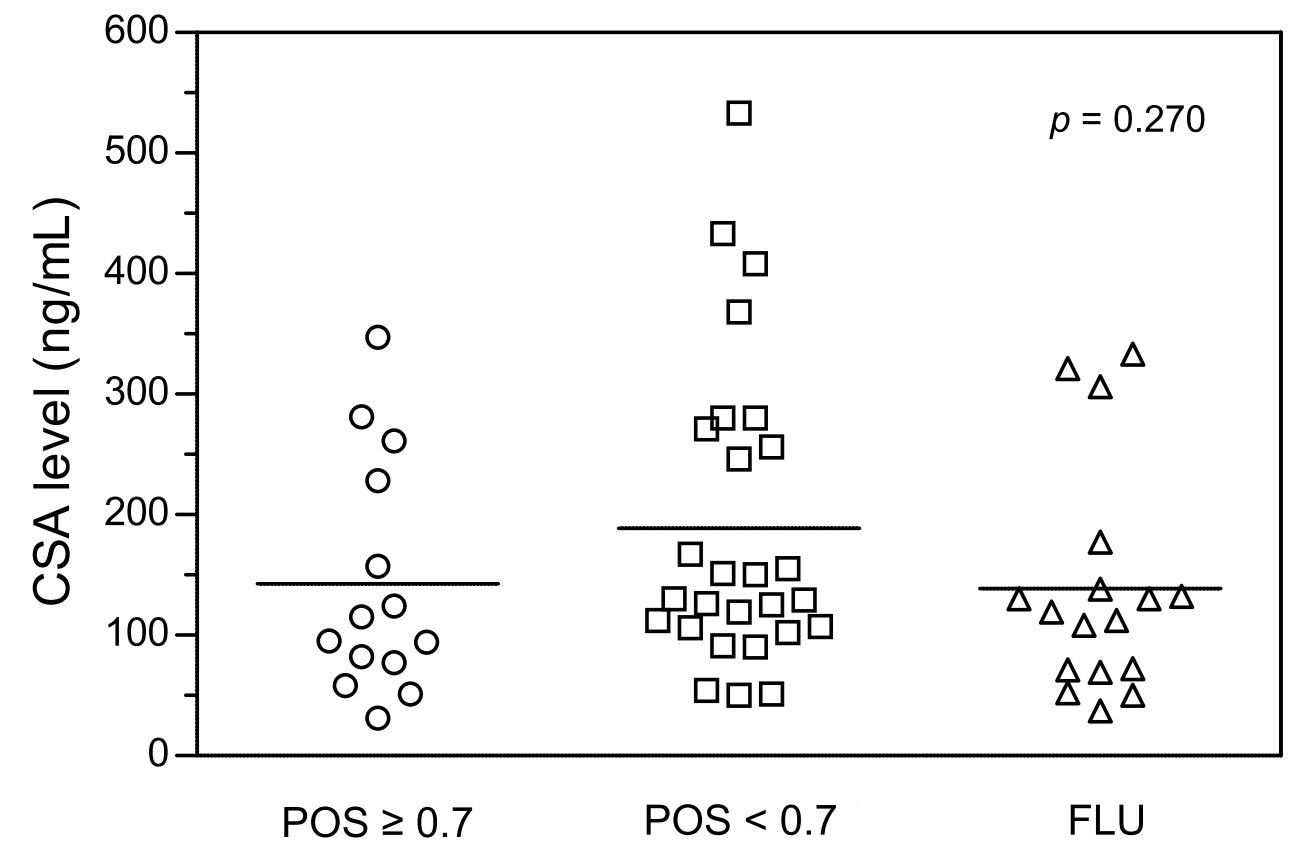

Figure 2 Cyclosporine levels of patients receiving azole antifungal drugs. 
Table 4 Overall Breakthrough Invasive Fungal Disease in Patients Receiving HSCTs

\begin{tabular}{|c|c|c|c|c|c|c|c|c|c|}
\hline Variable & Case I & Case 2 & Case 3 & Case 4 & Case 5 & Case 6 & Case 7 & Case 8 & Case 9 \\
\hline Sex/age (yr) & M/7.7 & $M / 5.9$ & $M / 5.8$ & $\mathrm{~F} / 7.7$ & $M / 16.6$ & $M / 14.8$ & F/II.7 & $M / 5.7$ & $M / 10.8$ \\
\hline Primary disease & SAA & $\begin{array}{c}\text { Relapsed } \\
\text { ALL }\end{array}$ & SAA & $\mathrm{HbE} / \beta^{0}$ & Relapsed ALL & Relapsed BAL & $\mathrm{HbE} / \beta^{0}$ & $\begin{array}{c}\text { Relapsed } \\
\text { AML }\end{array}$ & Relapsed ALL \\
\hline Donor/grafts & $\begin{array}{l}\text { MMSD/ } \\
\text { BM }\end{array}$ & MUD/PB & MUD/PB & MSD/BM & MSD/PB & MSD/PB & MUD/PB & MSD/BM & MSD/BM \\
\hline Engraftment & $\begin{array}{l}\text { Graft } \\
\text { failure }\end{array}$ & Day +14 & $\begin{array}{l}\text { Graft } \\
\text { failure }\end{array}$ & Day +24 & Day +14 & Day +16 & Day +32 & Day +16 & Day +33 \\
\hline Time-point post-HSCT & Day +10 & Day +20 & Day +27 & Day +33 & Day +34 & Day +116 & Day +|7| & Day +213 & Day +218 \\
\hline CMV reactivation (grade) & Grade 2 & Grade 3 & None & None & Grade 2 & Grade 3 & Grade 2 & None & None \\
\hline \multicolumn{10}{|l|}{ Host factors } \\
\hline Neutropenia $>10$ days & Yes & Yes & Yes & Yes & Yes & Yes & Yes & Yes & Yes \\
\hline $\begin{array}{l}\text { Hematological } \\
\text { malignancy }\end{array}$ & No & Yes & No & No & Yes & Yes & No & Yes & Yes \\
\hline Use of corticosteroids & No & Yes & No & No & No & Yes & Yes & No & Yes \\
\hline Immunosuppressants & Yes & Yes & Yes & Yes & Yes & Yes & Yes & Yes & Yes \\
\hline Acute/chronic GvHD & None & $\begin{array}{c}\text { Grade IV/ } \\
\text { cGvHD }\end{array}$ & None & None & None & Grade III & $\begin{array}{l}\text { Grade IV/ } \\
\text { cGvHD }\end{array}$ & None & Grade II \\
\hline $\begin{array}{l}\text { Pre-engraftment } \\
\text { prophylaxis }\end{array}$ & POS & POS & FLU & POS & POS & POS & POS & FLU & FLU \\
\hline $\begin{array}{l}\text { Post-engraftment } \\
\text { prophylaxis (day of } \\
\text { switching post-HSCT) }\end{array}$ & - & - & - & $\begin{array}{c}\text { FLU (Day } \\
+26)\end{array}$ & FLU (Day +17) & $\begin{array}{c}\text { FLU (Day } \\
+22)\end{array}$ & $\begin{array}{c}\text { FLU (Day } \\
+34)\end{array}$ & $\begin{array}{c}\text { FLU (Day } \\
+17)\end{array}$ & $\begin{array}{c}\text { FLU (Day } \\
+34)\end{array}$ \\
\hline POS level ( $\mu \mathrm{g} / \mathrm{mL})$ & 0.6 & 0.5 & - & 0.52 & 0.58 & 0.35 & 0.5 & - & - \\
\hline IFD category & Probable & Probable & Probable & Probable & Proven & Probable & Proven & Probable & Proven \\
\hline Pathogen & - & - & - & - & Mucor & - & Aspergillus & - & $\begin{array}{l}\text { Candida } \\
\text { albicans }\end{array}$ \\
\hline Site & $\begin{array}{l}\text { Lung } \\
\text { (imaging, } \\
\text { GM) }\end{array}$ & $\begin{array}{l}\text { Lung } \\
\text { (imaging, } \\
\text { GM) }\end{array}$ & $\begin{array}{l}\text { Lung } \\
\text { (imaging, } \\
\text { GM) }\end{array}$ & $\begin{array}{l}\text { Lung } \\
\text { (imaging, } \\
\text { GM) }\end{array}$ & $\begin{array}{l}\text { Small bowel } \\
\text { (histology); } \\
\text { lung (imaging) }\end{array}$ & $\begin{array}{c}\text { Lung } \\
\text { (imaging, GM) }\end{array}$ & $\begin{array}{l}\text { Skin, lung } \\
\text { (pus culture, } \\
\text { imaging) }\end{array}$ & $\begin{array}{c}\text { Lung } \\
\text { (imaging, GM) }\end{array}$ & $\begin{array}{l}\text { Blood } \\
\text { (culture) }\end{array}$ \\
\hline IFD outcome & PR & CR & PD & CR & PD & PD & PD & PD & PD \\
\hline Status & $\begin{array}{l}\text { Death } \\
\text { unrelated } \\
\text { to IFD }\end{array}$ & $\begin{array}{l}\text { Death } \\
\text { unrelated } \\
\text { to IFD }\end{array}$ & $\begin{array}{l}\text { Death } \\
\text { related } \\
\text { to IFD }\end{array}$ & Alive & $\begin{array}{l}\text { Death related } \\
\text { to IFD }\end{array}$ & $\begin{array}{l}\text { Death related } \\
\text { to IFD and } \\
\text { relapsed }\end{array}$ & $\begin{array}{l}\text { Death } \\
\text { related to } \\
\text { IFD }\end{array}$ & $\begin{array}{l}\text { Death related } \\
\text { to IFD and } \\
\text { relapsed }\end{array}$ & $\begin{array}{l}\text { Death related } \\
\text { to IFD and } \\
\text { relapsed }\end{array}$ \\
\hline
\end{tabular}

Abbreviations: ALL, acute lymphoblastic leukemia; AML, acute myeloid leukemia; BAL, biphenotypic acute leukemia; BM, bone marrow; CMV, cytomegalovirus; CR, complete response; FLU, fluconazole; GM, serum galactomannan; GvHD, graft-versus-host disease; HbE/ $\beta^{0}$, hemoglobin E-beta-thalassemia disease; HSCT, hematopoietic stem cell transplant; IFD, invasive fungal disease; MMSD, mismatched sibling donor; MSD, matched sibling donor; MUD, matched unrelated donor; PB, peripheral blood; PD, progressive disease; POS, posaconazole; PR, partial response; SAA, severe aplastic anemia.

detected after Day +100 post-HSCT. The mortality rate related to IFDs was $83 \%$.

Patient 5 experienced fever with acute respiratory distress syndrome, abdominal pain, and hematochezia 6 weeks after the HSCT. Laparotomy was performed, and a small bowel resection showed evidence of a mucormycosis infection from histology. A chest CT scan showed typical fungus lung infiltration, and a serum galactomannan assay was positive. However, there was no mycologic evidence to define the pathogen. He 
demonstrated no response to a combination of liposomal amphotericin B and voriconazole, and he died 10 weeks post-HSCT. Patient 7 developed cGvHD (skin and liver) 5 months post-HSCT and was treated with CsA plus prednisolone. She was readmitted with febrile neutropenia, leftknee swelling, and multiple abscesses on both legs. A pus culture from her skin and knee-joint fluid revealed Aspergillus spp. Despite receiving amphotericin B and voriconazole, she developed massive hemoptysis and died 2 weeks after her re-admission. Patient 9 had a relapse of acute lymphoblastic leukemia at 8 months post-HSCT and underwent salvage therapy. He suffered from fever and was given amphotericin B. Nevertheless, his blood cultures were persistently positive for Candida albicans, and he died 1 month after his re-admission.

As to probable IPA, only Patient 4 demonstrated a complete response to voriconazole. However, the 2 other cases had a disease relapse at 3 and 4 months postHSCT, and died within a month of commencing treatment with voriconazole.

\section{Discussion}

Currently, there is a clinical practice guideline for the use of echinocandin or a mold-active azole as an antifungal prophylaxis for pediatric patients receiving HSCTs. ${ }^{15}$ Some investigators have reported that mold-active azoles such as itraconazole, voriconazole, and POS have better efficacies in the pediatric population than FLU. ${ }^{19,20}$ From our data, the incidences of IFDs of the POS and FLU groups were comparable, at $5 \%$ and $3 \%$, respectively $(p=0.620)$. Doring also reported that POS, FLU, and itraconazole have comparable degrees of effectiveness in preventing IFD in patients with neutropenia. ${ }^{19}$ However, our study showed a significantly higher proportion of patients with a hematological malignancy in the POS group than the FLU group ( $37 \%$ vs $16 \% ; p=0.043)$. In addition, the rates of grades III and IV aGvHD were higher for the POS group than the FLU group (36\% vs $10 \%$; $p=$ 0.311). Regarding the host factors which increased the risk for IFDs, POS seemed to be more effective than FLU as an antifungal agent for the recipients during the preengraftment period. Moreover, $8 \%$ of patients receiving FLU post-engraftment had IFDs, and the mortality rate related to IFDs was $83 \%$. Whether using either POS or other mold-active agents during the post-engraftment period could further decrease the IFD incidence is an interesting research question.
The US Food and Drug Administration has approved the use of the oral suspension of POS as an antifungal agent for children older than 13 years. ${ }^{21}$ Many studies have since reported that the off-label use of POS for children younger than 13 demonstrated promising efficacy with a safety profile comparable to that for the adult population. $^{13,14,22}$ Doring reported the adverse events associated with using POS in pediatric patients with HSCTs. $^{23,24}$ Almost $7 \%$ of cases needed to discontinue the drug due to nausea and vomiting; furthermore, most patients developed abnormal liver function and required a CsA dose reduction of $22 \%$. In the current study, while $7 \%$ of our POS patients experienced nausea and vomiting, none had to discontinue POS. We also found that about $50 \%$ of our POS patients had increased levels of liver enzymes. Only $9 \%$ of our patients had a CsA overdose, which required a $25 \%$ dose reduction. The other $9 \%$ of our patients with CsA levels $<400 \mathrm{ug} / \mathrm{L}$ had renal insufficiency and needed to cease the use of CsA.

Although a trough level of $0.7 \mathrm{ng} / \mathrm{mL}$ is required for POS, most studies reported lower levels (0.383-0.438 ng/ $\mathrm{mL}$ ), with only $10-15 \%$ of their patients achieving the therapeutic level. ${ }^{24-27}$ The median POS level in our study was $0.5 \mathrm{ng} / \mathrm{mL} ; 19 \%$ of our patients reached a POS level $\geq 0.7 \mathrm{ng} / \mathrm{mL}$. Several investigators have attempted to solve the problem of failure to achieve the therapeutic level. Boonsathorn reported that the suspension form of POS had an inferior bioavailability - as low as $30 \%$ of the target level-to the tablet form. ${ }^{13}$ Tragiannidis also reported that $90 \%$ of patients attained the therapeutic target with the use of delayed-release POS tablets, and had no serious adverse events. ${ }^{28}$ Although those results are impressive, a further large study in the pediatric population is needed to clarify the pharmacokinetics of delayed-release POS tablets and to determine their effectiveness as an IFD prophylaxis.

The chief limitation of our study is that it was a retrospective study. It was conducted over a 20 -year period, during which different levels of supportive care were provided and the protocols for surveillance of adverse events varied. Moreover, the index of suspicion for IFD might have been lower during the first of the 2 decades, resulting in IFDs being under-detected. Furthermore, the higher percentage of hematological malignancy with POS might have increased the risk of IFDs, relative to FLU, during the preengraftment period. Lastly, the switching from POS to FLU after engraftment made it difficult to clarify the extent to 
which each drug contributed to the efficacy of IFD prophylaxis during the interchange period.

\section{Conclusions}

In summary, our study shows that POS and FLU have comparable levels of effectiveness, safety, and tolerability as IFD prophylaxes for children with allogeneic HSCTs during the pre-engraftment phase. Establishing the optimum dose and duration of POS in this setting requires further investigation using a larger pediatric population.

\section{Acknowledgments}

The authors acknowledge the expert care provided to patients by the staff of the Department of Pediatrics at Siriraj Hospital.

\section{Disclosure}

The abstract of this paper was presented at the 45th Annual Meeting of the European Society for Blood and Marrow Transplantation. Entitled "Antifungal prophylaxis with posaconazole versus fluconazole in children with neutropenia following hematopoietic stem cell transplantation", it was given as a poster presentation with interim findings. The abstract was published in the "Physicians-Poster Session" of the 24-27 March 2019 publication of the journal, "Bone Marrow Transplantation": https://doi.org/10. 1038/s41409-019-0559-4. All authors reported no conflicts of interest for this work.

\section{References}

1. Kriengkauykiat J, Ito JI, Dadwal SS. Epidemiology and treatment approaches in management of invasive fungal infections. Clin Epidemiol. 2011;3:175-191.

2. Camps IR. Risk factors for invasive fungal infections in haematopoietic stem cell transplantation. Int J Antimicrob Agents. 2008;32(Suppl 2):S119-23.

3. Safdar A, Rodriguez $\mathrm{GH}$, Mihu $\mathrm{CN}$, et al. Infections in non-myeloablative hematopoietic stem cell transplantation patients with lymphoid malignancies: spectrum of infections, predictors of outcome and proposed guidelines for fungal infection prevention. Bone Marrow Transplant. 2010;45(2):339-347.

4. Kontoyiannis DP, Marr KA, Park BJ, et al. Prospective surveillance for invasive fungal infections in hematopoietic stem cell transplant recipients, 2001-2006: overview of the Transplant-Associated Infection Surveillance Network (TRANSNET) Database. Clin Infect Dis. 2010;50(8):1091-1100.

5. Neofytos D, Horn D, Anaissie E, et al. Epidemiology and outcome of invasive fungal infection in adult hematopoietic stem cell transplant recipients: analysis of Multicenter Prospective Antifungal Therapy (PATH) Alliance registry. Clin Infect Dis. 2009;48(3):265-273.

6. Phikulsod P, Suwannawiboon B, Chayakulkeeree M. Invasive fungal infection among febrile patients with chemotherapy-induced neutropenia in Thailand. Southeast Asian J Trop Med Public Health. 2017;48 (1):159-169.
7. Goodman JL, Winston DJ, Greenfield RA, et al. A controlled trial of fluconazole to prevent fungal infections in patients undergoing bone marrow transplantation. $N$ Engl J Med. 1992;326(13):845-851.

8. Ullmann AJ, Lipton JH, Vesole DH, et al. Posaconazole or fluconazole for prophylaxis in severe graft-versus-host disease. $N$ Engl J Med. 2007;356(4):335-347.

9. Cornely OA, Maertens J, Winston DJ, et al. Posaconazole vs. fluconazole or itraconazole prophylaxis in patients with neutropenia. $N$ Engl J Med. 2007;356(4):348-359.

10. Dekkers BGJ, Bakker M, van der Elst KCM, et al. Therapeutic drug monitoring of posaconazole: an update. Curr Fungal Infect Rep. 2016;10:51-61.

11. Petitcollin A, Boglione-Kerrien C, Tron C, et al. Population pharmacokinetics of posaconazole tablets and monte carlo simulations to determine whether all patients should receive the same dose. Antimicrob Agents Chemother. 2017;61(11):e01166-e01217.

12. Chen L, Krekels EHJ, Verweij PE, et al. Pharmacokinetics and pharmacodynamics of posaconazole. Drugs. 2020;80(7):671-695.

13. Boonsathorn S, Cheng I, Kloprogge F, et al. Clinical pharmacokinetics and dose recommendations for posaconazole in infants and children. Clin Pharmacokinet. 2019;58(1):53-61.

14. Vicenzi EB, Calore E, Decembrino N, et al. Posaconazole oral dose and plasma levels in pediatric hematology-oncology patients. Eur J Haematol. 2018;100(3):315-322.

15. Lehrnbecher T, Fisher BT, Phillips B, et al. Clinical practice guideline for systemic antifungal prophylaxis in pediatric patients with cancer and hematopoietic stem-cell transplantation recipients. J Clin Oncol. 2020;38(27):3205-3216.

16. U.S. Deprment of Health and Human Services NioH, National Cancer Institute. Common Terminology Criteria for Adverse Events (CTCAE). Version 5.0; 2017 [cited January 4, 2021]. Available from: https:/ctep. cancer.gov/protocolDevelopment/electronic_applications/docs/ CTCAE_v5_Quick_Reference_8.5x11.pdf. Accessed July 20, 2021.

17. Donnelly JP, Chen SC, Kauffman CA, et al. Revision and update of the consensus definitions of invasive fungal disease from the European Organization for Research and Treatment of Cancer and the Mycoses Study Group Education and Research Consortium. Clin Infect Dis. 2020;71(6):1367-1376.

18. Segal BH, Herbrecht R, Stevens DA, et al. Defining responses to therapy and study outcomes in clinical trials of invasive fungal diseases: mycoses Study Group and European organization for research and treatment of cancer consensus criteria. Clin Infect Dis. 2008;47(5):674-683.

19. Döring M, Eikemeier M, Cabanillas SKM, et al. Antifungal prophylaxis with posaconazole vs. fluconazole or itraconazole in pediatric patients with neutropenia. Eur J Clin Microbiol Infect Dis. 2015;34 (6):1189-1200.

20. Science M, Robinson PD, MacDonald T, et al. Guideline for primary antifungal prophylaxis for pediatric patients with cancer or hematopoietic stem cell transplant recipients. Pediatr Blood Cancer. 2014;61 (3):393-400.

21. FDA. U.S. Noxafl instruction 2015. U.S.: FDA; [cited January 4, 2021]. Available from: https://www.accessdata.fda.gov/drugsatfda docs/label/2014/205053s1lbl.pdf. Accessed July 20, 2021.

22. Döring M, Cabanillas SKM, Klinker H, et al. Posaconazole plasma concentrations in pediatric patients receiving antifungal prophylaxis during neutropenia. Med Mycol. 2017;55(4):375-384.

23. Döring M, Blume O, Haufe S, et al. Comparison of itraconazole, voriconazole, and posaconazole as oral antifungal prophylaxis in pediatric patients following allogeneic hematopoietic stem cell transplantation. Eur J Clin Microbiol Infect Dis. 2014;33 (4):629-638.

24. Döring M, Müller C, Johann PD, et al. Analysis of posaconazole as oral antifungal prophylaxis in pediatric patients under 12 years of age following allogeneic stem cell transplantation. BMC Infect Dis. 2012;12:263. 
25. Vanstraelen K, Colita A, Bica AM, et al. Pharmacokinetics of posaconazole oral suspension in children dosed according to body surface area. Pediatr Infect Dis J. 2016;35(2):183-188.

26. McMahon J, Théorêt Y, Autmizguine J, et al. Posaconazole plasma monitoring in immunocompromised children. J Pediatric Infect Dis Soc. 2017;6(4):389-392.

27. Heinz WJ, Cabanillas Stanchi KM, Klinker H, et al. Posaconazole plasma concentration in pediatric patients receiving antifungal prophylaxis after allogeneic hematopoietic stem cell transplantation. Med Mycol. 2016;54(2):128-137.
28. Tragiannidis A, Herbrüggen $\mathrm{H}$, Ahlmann $\mathrm{M}$, et al. Plasma exposures following posaconazole delayed-release tablets in immunocompromised children and adolescents. J Antimicrob Chemother. 2019;74 (12):3573-3578.

\section{Publish your work in this journal}

The Journal of Blood Medicine is an international, peer-reviewed, open access, online journal publishing laboratory, experimental and clinical aspects of all aspect pertaining to blood based medicine including but not limited to: Transfusion Medicine; Blood collection, Donor issues, Transmittable diseases, and Blood banking logistics; Immunohematology; Artificial and alternative blood based therapeutics; Hematology; Biotechnology/nanotechnology of blood related medicine; Legal aspects of blood medicine; Historical perspectives. The manuscript management system is completely online and includes a very quick and fair peer-review system. Visit http://www.dovepress.com/testimonials.php to read real quotes from published authors. 